\title{
Langmuir
}

This document is confidential and is proprietary to the American Chemical Society and its authors. Do not copy or disclose without written permission. If you have received this item in error, notify the sender and delete all copies.

\section{Hybrid polymer-lipid films as platforms for directed membrane protein insertion}

\begin{tabular}{|r|l|}
\hline Journal: & Langmuir \\
\hline Manuscript ID: & la-2015-00388b.R1 \\
\hline Manuscript Type: & Article \\
\hline Date Submitted by the Author: & 27-Mar-2015 \\
\hline Complete List of Authors: & $\begin{array}{l}\text { Kowal, Justyna; University of Basel, Department of Chemistry } \\
\text { Wu, Dalin; Department of Chemistry, University of Basel, } \\
\text { Mikhalevich, Viktoria; University of Basel, Department of Chemistry } \\
\text { Palivan, Cornelia; University of Basel, Chemistry Department } \\
\text { Meier, Wolfgang; University of Basel, Department of Chemistry }\end{array}$ \\
\hline
\end{tabular}

\section{SCHOLARONE ${ }^{m}$ \\ Manuscripts}




\title{
Hybrid polymer-lipid films as platforms for
}

\section{directed membrane protein insertion}

\author{
Justyna Kowal, ${ }^{a}$ Dalin Wu, ${ }^{a}$ Viktoria Mikhalevich, ${ }^{a}$ Cornelia G. Palivan, ${ }^{a}$ Wolfgang Meier ${ }^{a} *$ \\ ${ }^{\text {a }}$ Chemistry Department, University of Basel, Klingelbergstrasse 80, 4056 Basel, Switzerland
}

\begin{abstract}
Hybrids composed of amphiphilic block copolymers and lipids constitute a new generation of biological membrane-inspired materials. Hybrid membranes resulting from self-assembly of lipids and polymers represent adjustable models for interactions between artificial and natural membranes, which are of key importance, e.g. when developing systems for drug delivery. By combining poly(dimethylsiloxane)-block-poly(2-methyl-2-oxazoline) amphiphilic copolymers (PDMS- $b$-PMOXA) with various phospholipids we obtained hybrid films with modulated properties and topology, based on phase separation, and the formation of distinct domains. By understanding the factors driving the phase separation in these hybrid lipid-polymer films, we were able to use them as platforms for directed insertion of membrane proteins. Tuning the composition of the polymer-lipids mixtures favored successful insertion of membrane proteins with desired topological distributions (in polymer or/and lipid regions). Controlled insertion and location of membrane proteins in hybrid films make these hybrids ideal candidates for numerous applications where specific spatial functionality is required.
\end{abstract}

\section{INTRODUCTION}

Biological membranes are complex, multi-component assemblies, which have inspired the development of artificial compartments and active surfaces for applications in medicine, 
ecology, and catalysis. Membrane mimics have been developed from phospholipids, the most abundant components of biological membranes, ${ }^{1,2}$ but recently it has been shown that amphiphilic block copolymers are better candidates for generating membrane models, since they surpass membranes based on phospholipids in terms of stability, permeability and flexibility, due to their higher molecular weights. ${ }^{3}$ A great advantage of amphiphilic block copolymers is the availability of a wide choice of monomers, and the possibility of varying the length of both the hydrophilic and hydrophobic blocks to design macromolecules with desired properties. ${ }^{4-6}$ A promising alternative for producing membranes with triggered properties is to develop hybrid systems composed of mixed lipids and amphiphilic block copolymers. ${ }^{7,8}$ This combination allows the generation of desired properties for materials, by combining the robustness of amphiphilic block copolymers with the biocompatibility of phospholipids. ${ }^{9}$ In this respect, the presence of thicker amphiphilic block copolymer domains in mixed films influences the stability and permeability of such hybrid systems. ${ }^{10}$ By choosing an appropriate composition, the number and distribution of receptor or ligand molecules in the mixture can be regulated and thus a system can possess either repulsion or binding properties. $^{11,12}$ Heterogeneous membranes can serve as the models to understand the membrane related processes, such as receptor/ligand recognition, or to investigate the interfacial interactions. On the other hand they can find many applications, for instance as the drug delivery systems, where the hybrid vesicle has stability high enough to resist its structure after introduction into the cardiovascular system and the release rate of encapsulated species can be tuned by varying the ratio of polymer and phospholipid.

An interesting approach is to form membrane mimics with "raft-like" domains, which are known to participate in important processes in biological membranes, such as lateral protein organization, virus uptake, or membrane tension regulation. ${ }^{13}$ It has been shown that by mixing of lipids with amphiphilic copolymers a heterogeneous membrane is obtained, where the composition and formation of domains strictly depends on the structures and phase 
transition temperatures $\left(\mathrm{T}_{\mathrm{m}}\right)$ of polymer and lipid, their molar ratio, and the temperature of membrane formation. ${ }^{9,10,14}$ For example, Gettel et al. studied the hybrid materials composed of poly(butadiene)-block-poly(ethylene oxide) (PBD-b-PEO) and 1-palmitoyl-2-oleoyl-snglycero-3-phosphocholine (POPC), in which no phase separation could be observed in the whole molar ratios range. ${ }^{15}$ It was due to the fact that POPC is an unsaturated phospholipid $\left(\mathrm{T}_{\mathrm{m}}=-2{ }^{\circ} \mathrm{C}\right)$ forming monolayers in the liquid expanded state, which indicates higher fluidity of such monolayer. ${ }^{16}$ PBD- $b$-PEO forming monolayers in the same sate, was thus able to form homogeneous membrane without any observable in microscale domains. It was shown that the state and composition of the mixture components has a crucial influence on domains formation. Heterogeneous membranes were obtained by mixing poly(isobutylene)-blockpoly(ethylene oxide) block copolymers with 1,2-dihexadecanoyl-sn-glycero-3phosphocholine (DPPC) only when the content of polymer in the mixture was ranging from 20 to $28 \mathrm{~mol} \%$, while when polymer was mixed with 1,2-dioleoyl-sn-glycero-3phosphocholine (DOPC), no domains formation occurred, but vesicles underwent a fission. ${ }^{11}$ Similar results were obtained in the studies of poly(dimethylsiloxane)-graft-poly(ethylene oxide) (PDMS- $b$-PEO) mixed with DPPC and POPC. Also in this case large domains appeared only in the mixtures of copolymer with DPPC, where the copolymer content ranged from 50 to $80 \mathrm{~mol} \%{ }^{9}$ These studies show that domain formation occurs in mixtures, where the $\mathrm{T}_{\mathrm{m}}$ difference between two components is high, like in case of mixtures composed of copolymer and DPPC. The mixture composition at which the domains could be observed depended on such properties of the copolymer as structure and molecular weight. Recently, Dao et al. studied the domain formation at the nanoscale in hybrid large unilamellar vesicles (LUVs) composed of PDMS- $b$-PEO and DPPC or POPC. ${ }^{17}$ In order to reduce the line tension, which arises from the thickness differences, the copolymer with low molecular weight was used. The authors showed that a nanoscale separation can be obtained whatever the state of the lipid is. In addition no vesicle fission was observed, as it was in case of studies performed 
on giant unilamellar vesicles, ${ }^{9}$ which indicated that the membrane curvature influences the stabilization of nanodomains.

A step further in this strategy is introduction of biomolecules, e.g. membrane proteins, into the hybrid membrane to produce materials with desired properties and functions. By incorporation of the membrane protein into heterogeneous membrane the location and concentration of the protein can be controlled, which enables modulation of the membrane permeability and biocompatibility. In addition, two or more biomolecules could be inserted into different phases of such hybrid membrane. Such membrane modifications enable development of advanced and functional materials with intended responsiveness for applications in nanomedicine. For example, hybrid materials composed of poly(ethylene oxide)-block-poly(butylene oxide) and ganglioside-functionalized DPPC have been successfully used for molecular recognition of the cholera toxin B, which binds specifically to ganglioside. ${ }^{12}$ The composition of the mixture played a crucial role in modulating the binding of the protein, and resulted in a model for studying receptor/ligand recognition. ${ }^{12}$ However, the binding of the protein was driven by interaction with a specific receptor, and thus was not spontaneous. The first example of spontaneous insertion of a membrane protein into a hybrid polymer-lipid membrane was the outer membrane protein $\mathrm{F}(\mathrm{OmpF})$ in membrane composed of PMOXA- $b$-PDMS- $b$-PMOXA triblock copolymer and DPPC. Interestingly, OmpF distributed preferentially in the polymer-rich phase, ${ }^{18}$ but there was no report of a systematic investigation, which is of crucial importance for the development of bio-hybrid membranes with potential for specific applications. There are still open questions regarding the specific molecular properties of each component of the mixture that are needed for insertion of a membrane protein in a desired location, or for supporting its functionality inside a heterogeneous synthetic material.

We now present hybrid materials, which allow directed and spontaneous insertion of membrane proteins. These hybrid membranes are based on mixtures of amphiphilic diblock 
copolymers with lipids having different molecular properties. Our interest was to establish whether membrane proteins can be inserted into such hybrid membranes, to determine where they are located upon insertion, and to control a desired position for different morphological properties of the membrane. We prepared the mixtures by using three PDMS- $b$-PMOXA diblock copolymers with different hydrophobic block lengths (16, 37, and 65 PDMS units), and various lipids (DPPC, DOPC, 1,2-dipalmitoyl-sn-glycero-3-phosphoethanolamine (DPPE), and 1-palmitoyl-2-oleoyl-sn-glycero-3-phosphoethanolamine (POPE)) with a different degree of saturation and head groups. We chose PDMS- $b$-PMOXA diblock copolymer as a good candidate for forming hybrid membranes with lipids, because it is nontoxic, biocompatible, and highly flexible, and thus suitable for the development of biomaterials. ${ }^{19}$ PMOXA is a biologically-inspired polymer with structural similarity to polypeptides. ${ }^{20}$ It is highly stable in biological environments because of the tertiary amide in its backbone chain, which is not easily recognized and hydrolyzed by enzymes. ${ }^{21}$ By characterizing the membranes formed by binary mixtures with different ratios of components, we were able to establish the conditions under which the hybrid membranes formed distinct domains of lipid- and polymer-rich phases. First, Brewster angle microscopy (BAM) and confocal laser scanning microscopy (CLSM) were used to establish the formation and morphology of the mixed monolayers generated by the Langmuir technique and transferred to transparent substrates. Then the distribution of cyclic nucleotide-modulated potassium channels from Mesorhizobium loti (MloK1) ${ }^{22}$ within the membrane was assessed. MloK1 was selected as a model membrane protein because it has been already successfully inserted into a solid-supported membrane based on a pure PDMS- $b$-PMOXA diblock copolymer. ${ }^{23}$ We now show that by modulating the composition of the mixture, i.e. polymer size, lipid, and ratio of components, that a film with different morphology is obtained, and that insertion of the protein is directly related to the state of the phase. This strategy of developing mixed lipid- 
polymer membranes with inserted proteins is a straightforward way to control a topologic distribution of biomolecules within a hybrid material.

\section{MATERIALS AND METHODS}

\subsection{PDMS- $b$-PMOXA diblock copolymers}

PDMS- $b$-PMOXA block copolymers were synthetized accordingly to the procedures described previously. ${ }^{24,25}$ In brief, PDMS-OH was synthetized by the hydrosilation reaction, ${ }^{26}$ then activated by trifluoromethanesulfonic anhydride, and used as the macroinitiator for cationic ring-opening polymerization of 2-methyl-2oxazoline. We used polymers with different PDMS block lengths, i.e. $\mathrm{PDMS}_{65}-b$-PMOXA $12\left(\mathrm{M}_{\mathrm{w}}=5735 \mathrm{~g} \mathrm{~mol}^{-1}\right.$, PDI = 1.67), $\mathrm{PDMS}_{37}-b-\mathrm{PMOXA}_{9}\left(\mathrm{M}_{\mathrm{w}}=3704 \mathrm{~g} \mathrm{~mol}^{-1}, \mathrm{PDI}=1.44\right), \mathrm{PDMS}_{16}-b-\mathrm{PMOXA}_{9}\left(\mathrm{M}_{\mathrm{w}}=2151 \mathrm{~g}\right.$ $\mathrm{mol}^{-1}$, PDI $=1.56$ ). Molecular weights were calculated from ${ }^{1} \mathrm{H}$ NMR spectra (Figure S1, Supporting Information), and PDI was established from GPC data.

For the CLSM experiments we used copolymers labeled with the fluorescent dye, sulforodhamine B acid chloride (SRB) (Aldrich), which was linked to the hydroxyl end-group of the polymer. ${ }^{1} \mathrm{H}$ NMR and ATR-FTIR measurements indicated that no structural reorganization of the polymer occurred after labeling (Figure S1 and S2, Supporting Information).

\subsection{Lipids}

$\operatorname{DPPC}\left(\mathrm{M}_{\mathrm{w}}=734 \mathrm{~g} \mathrm{~mol}^{-1}, \mathrm{~T}_{\mathrm{m}}=41^{\circ} \mathrm{C}\right), \operatorname{DOPC}\left(\mathrm{M}_{\mathrm{w}}=786 \mathrm{~g} \mathrm{~mol}^{-1}, \mathrm{~T}_{\mathrm{m}}=-17{ }^{\circ} \mathrm{C}\right), \operatorname{DPPE}$ $\left(\mathrm{M}_{\mathrm{w}}=692 \mathrm{~g} \mathrm{~mol}^{-1}, \mathrm{~T}_{\mathrm{m}}=63{ }^{\circ} \mathrm{C}\right)$, and POPE $\left(\mathrm{M}_{\mathrm{w}}=718 \mathrm{~g} \mathrm{~mol}^{-1}, \mathrm{~T}_{\mathrm{m}}=25{ }^{\circ} \mathrm{C}\right)$ were purchased from Avanti Polar Lipids, Inc. For the experiments, lipid solutions with concentration of $1 \mathrm{mg}$ $\mathrm{ml}^{-1}$ were prepared. DPPC, DOPC, and POPE were dissolved in chloroform, whereas a mixture of chloroform and methanol (v/v, 9:1) was used for DPPE. 


\subsection{Membrane protein}

We used the full-length, cyclic nucleotide-modulated, potassium channel from Mesorhizobium loti (MloK1) $)^{22,27}$ as the model membrane protein. MloK1 was expressed and purified to homogeneity as described by Kowal et al. ${ }^{22}$ The protein was dissolved in Bicine buffer (20 mM Bicine pH 7.6, $20 \mathrm{mM} \mathrm{KCl,} 200 \mu \mathrm{M}$ 3'-5'-cyclic adenosine monophosphate (cAMP, Sigma-Aldrich), $0.4 \%$ n-decyl- $\beta$-D-maltopyranoside (DM, Affymetrix)), and then labeled with green fluorescent dye (DyLight 488, Thermo Fisher Scientific) at its primary amine. ${ }^{23}$ Briefly, the dye solution $\left(10 \mu \mathrm{l}, 1 \mathrm{mg} \mathrm{ml}^{-1}\right.$ in DMSO) was added to MloK1 (500 $\mu$, $0.45 \mathrm{mg} \mathrm{ml}^{-1}$ ) dropwise, and stirred for 2 hours, and the protein purified from free dye by dialysis (MWCO $10 \mathrm{kDa}$ ) against Bicine buffer for 5 days at $6{ }^{\circ} \mathrm{C}$.

\subsection{Langmuir isotherms}

Surface pressure-area isotherms were recorded using a Langmuir Teflon ${ }^{\circledR}$ trough (KSV Instruments Ltd., Finland) with an area of $420 \mathrm{~cm}^{2}$. The trough was equipped with two movable, hydrophilic Delrin ${ }^{\circledR}$ barriers and a Wilhelmy plate made of ashless filter paper. Prior to making the measurements, the trough was cleaned with high purity chloroform (HPLCgrade, Sigma-Aldrich) and ethanol $(\leq 99.8 \%$, Fluka), and the barriers were cleaned with ethanol and ultrapure water. All measurements were performed with ultrapure water as the subphase. The solution of amphiphiles was spread at the air-water interface using a glass Hamilton microsyringe, and the solvent was allowed to evaporate for $10 \mathrm{~min}$, after which the film was compressed with a rate of $10 \mathrm{~mm} \mathrm{~min}^{-1}$. All isotherms were recorded at $23{ }^{\circ} \mathrm{C}$, and each measurement was repeated at least three times.

The physical state of the monolayers was established by calculating a compressibility modulus from the surface pressure-area isotherms as $C_{s}^{-1}=-\mathrm{A}(\partial \pi / \partial \mathrm{A})_{\mathrm{T}}$, where $\mathrm{A}$ is the mean molecular area $\left(\AA^{2}\right.$ molecule $\left.{ }^{-1}\right), \pi$ is the surface pressure $\left(\mathrm{mN} \mathrm{m}^{-1}\right)$, and $\mathrm{T}$ is the temperature $\left({ }^{\circ} \mathrm{C}\right) .{ }^{28}$ 


\subsection{Preparation of solid substrates}

Glass cover slips (Menzel-Gläser, Germany) and silica wafers (Si-Mat Silicon Materials, Germany) were cleaned by sonication for $1 \mathrm{~h}$ in chloroform and $1 \mathrm{~h}$ in ethanol, and then dried with a stream of nitrogen.

\subsection{Langmuir-Blodgett transfers}

Amphiphile monolayers were transferred from the air-water interface by the LangmuirBlodgett (LB) method. For this purpose we used a Mini-trough (KSV Instruments Ltd., Finland) with a surface area of $242 \mathrm{~cm}^{2}$. In order to perform the LB transfer, the solid substrate was placed in the aqueous subphase, and the monolayer at the air-water interface then compressed to a surface pressure of $35 \mathrm{mN} \mathrm{m}^{-1}$. After $15 \mathrm{~min}$ of stabilization the monolayer was transferred to the substrate with a constant dipper speed of $0.5 \mathrm{~mm} \mathrm{~min}^{-1}$.

To transfer the monolayer with added protein, the polymer-lipid mixture was first compressed to a surface pressure of $20 \mathrm{mN} \mathrm{m}^{-1}$, then after $10 \mathrm{~min}$ of stabilization, $5.2 \mu \mathrm{g}$ of labeled protein dissolved in Bicine buffer was added dropwise onto the monolayer surface (Figure S3, Supporting Information) and allowed to stabilize for $20 \mathrm{~min}$. After this time the monolayer was compressed to $35 \mathrm{mN} \mathrm{m}^{-1}$ and transferred to glass.

\subsection{Brewster Angle Microscopy (BAM)}

Compression of the amphiphile monolayers at the air-water interface was monitored by a Brewster angle microscope $\left(\mathrm{EP}^{3} \mathrm{SW}\right.$ system, Nanofilm Technologie GmbH, Göttingen, Germany) equipped with a Nd-YAG laser $(\lambda=532 \mathrm{~nm})$, long distance objective (Nikon, 20x), and monochrome CCD camera. The size of the Brewster angle microscopy (BAM) image corresponds to $220 \times 250 \mu \mathrm{m}^{2}$, with a resolution of $1 \mu \mathrm{m}$. 


\subsection{Confocal Laser Scanning Microscopy (CLSM)}

Mixed polymer-lipid films transferred to glass were imaged by CLSM (Zeiss LSM 510META/Confocor2, Germany). The polymer solutions used for preparation of the mixtures contained 5\% of SRB-labeled polymer, and a glass cover slip with the transferred film was placed on a cleaned microscope slide so that the transferred film was enclosed between two slides. After adjusting the microscope to produce a sharp image, the sample was scanned randomly throughout the surface. All measurements were performed at room temperature using a HeNe laser $(543 \mathrm{~nm})$ as the excitation source, and a 40x water-immersion objective (Zeiss C-Apochromat 40x, NA 1.2); the excitation transmission of the HeNe laser was set for $20 \%$.

In order to measure the distribution of the protein within the mixed film, we prepared films with SRB-labeled polymer and DyLight 488-labeled protein, and performed measurements in two channels, i.e. one channel by using the same settings as for mixtures without protein, and the other channel using an Ar laser (488 nm) as excitation source, with excitation transmission set for $4 \%$. In this way we could overlap two micrographs of the same area, presenting signals from the two different dyes.

\subsection{Ellipsometry}

The thickness of the monolayers formed from pure polymer or lipid transferred to silica slides was measured with an $\mathrm{EP}^{3} \mathrm{SW}$ imaging ellipsometer (Nanofilm Technologie GmbH, Göttingen, Germany). Measurements were performed for 10 incident angles ranging from $55^{\circ}$ to $75^{\circ}$, and the thickness of the silicon dioxide layer $(\sim 2 \mathrm{~nm})$ was taken into account when estimating the film thickness. The refractive index value of 1.5 was used for both the polymer and lipid films.

\section{RESULTS AND DISCUSSION}




\subsection{Strategy for developing hybrid materials with inserted proteins}

Our goal was to direct membrane protein distribution in hybrid materials by choosing appropriate compositions for the binary lipid-polymer mixtures. First it was necessary to investigate the polymer-lipid mixture to determine the state of the monolayer, and the conditions under which it is possible to obtain a phase separation between lipids and polymers to form separate domains of each component. Three copolymers with a similar number of PMOXA units and various numbers of PDMS units $\left(\mathrm{PDMS}_{65}-b-\mathrm{PMOXA}_{12}, \mathrm{PDMS}_{37}-b-\right.$ $\left.\mathrm{PMOXA}_{9}, \mathrm{PDMS}_{16}-b-\mathrm{PMOXA}_{9}\right)$ were selected for preparation of hybrid membranes. Two pairs of lipids, i.e. DPPC - DOPC, and DPPE - POPE, were chosen because PC and PE are the most abundant phospholipid building blocks in biological membranes. ${ }^{29}$ DPPC and DPPE have both hydrocarbon chains saturated, POPE has one saturated and one unsaturated chain, whereas DOPC is an unsaturated lipid. This selection of lipids allowed us to investigate the influence of saturation degree on the phase separation of lipid and polymer, and thus domain formation. On the other hand, we were interested in examining the influence of the hydrophilic head group of the lipid on the mixing properties of lipid-polymer systems, and thus chose PC and PE, which have different sizes and orientations at the air-water interface. ${ }^{30}$ Protein insertion strongly depends on the phase state, and in natural membranes most membrane proteins are located in the regions containing unsaturated lipids, which are more fluid than saturated lipids, e.g. MloK1 was reconstituted in POPE. For this reason, we expected that depending on the mixture composition, the protein would be preferentially distributed in a more liquid phase.

\subsection{Surface pressure-area isotherms of pure amphiphiles}

In order to better understand the mixing properties of lipids with amphiphilic block copolymers, we investigated the behavior of pure components at the air-water interface by compression of Langmuir monolayers (Table 1). 
Table 1. Monolayer parameters for investigated lipids and polymers.

\begin{tabular}{|c|c|c|c|c|c|c|c|}
\hline Parameter & DPPC & DOPC & DPPE & POPE & $\mathbf{A}_{\mathbf{6 5}} \mathbf{B}_{\mathbf{1 2}}{ }^{(\mathbf{1})}$ & $\mathbf{A}_{\mathbf{3 7}} \mathbf{B}_{\mathbf{9}}{ }^{(\mathbf{1})}$ & $\mathbf{A}_{\mathbf{1 6}} \mathbf{B}_{\mathbf{9}}{ }^{(\mathbf{1})}$ \\
\hline Molar mass $\left[\mathrm{g} \mathrm{mol}^{-1}\right]$ & 734 & 786 & 692 & 718 & 5735 & 3704 & 2151 \\
\hline $\mathrm{d}[\mathrm{nm}]^{(2)}$ & 2.1 & 2.0 & 2.5 & 1.6 & 6.5 & 4.5 & 1.8 \\
\hline $\mathrm{Mma}_{\text {lift-off }}\left[\AA^{2}\right]$ & 97 & 125 & 51 & 92 & 1082 & 800 & 400 \\
\hline $\mathrm{Mma}_{\text {col }}\left[\AA^{2}\right]$ & 37 & 57 & 36 & 33 & 60 & 53 & 55 \\
\hline$\pi_{\text {col }}\left[\mathrm{mN} \mathrm{m}^{-1}\right]^{(3)}$ & 55 & 47 & 50 & 51 & 53 & 45 & 43 \\
\hline$C_{s}^{-1}\left[\mathrm{mN} \mathrm{m}^{-1}\right]^{(4)}$ & 184 & 95 & 514 & 48 & 45 & 42 & 34 \\
\hline Monolayer state $^{(4)}$ & LC & L & S & LE & LE & LE & LE \\
\hline
\end{tabular}

(1) "A" corresponds to PDMS, and "B" to PMOXA block of the diblock copolymer; (2) established from ellipsometry with an error of $\pm 0.05 \mathrm{~nm} ;{ }^{(3)} \Pi_{\mathrm{col}}$ - surface pressure of collapse point; ${ }^{(4)}$ established for the surface pressure at which maximum compressibility modulus value appears.

Compression of DPPE monolayers was completed in a short range of mean molecular areas, i.e. the lift-off area of DPPE isotherm was at mean molecular area of $51 \AA^{2}$, whilst the collapse point at $36 \AA^{2}$ resulted in the steep slope of the isotherm. This indicated a solid state monolayer (Figure S4, Supporting Information). ${ }^{31}$ Indeed the calculated compressibility modulus value of $514 \mathrm{mN} \mathrm{m}^{-1}$ corresponds to a solid state DPPE monolayer. The Langmuir isotherm of DPPC was longer than that of DPPE, and possessed a characteristic plateau due to the transition from a liquid-expanded (LE) to a liquid-condensed state (LC). ${ }^{32}$ This transition has been observed in BAM as a result of the formation of flower-shaped structures in the plateau area (Figure S5, Supporting Information). At high surface pressure, the film became homogeneous and the compressibility modulus of the DPPC monolayer reached $184 \mathrm{mN} \mathrm{m}^{-1}$, which corresponds to a LC state.

The isotherms of both unsaturated lipids had higher lift-off areas than their saturated equivalents (92 $\AA^{2}$ for POPE and $125 \AA^{2}$ for DOPC), because the double bond in the hydrocarbon chain limits its flexibility, and decreases adhesion between molecules, so that they occupy a larger area within the monolayer. ${ }^{33,34}$ During compression, POPE exhibited a transition at a surface pressure of $36 \mathrm{mN} \mathrm{m}^{-1},{ }^{35}$ which was well pronounced in the 
compressibility modulus graph (Figure S6, Supporting Information). The $C_{s}^{-1}$ value indicated that at this point the monolayer changed its physical state from LC $\left(C_{S}^{-1}=120 \mathrm{mN} \mathrm{m}^{-1}\right)$ to LE $\left(C_{s}^{-1}=48 \mathrm{mN} \mathrm{m}^{-1}\right)$. The DOPC monolayer was in the liquid state with $C_{s}^{-1}=95 \mathrm{mN} \mathrm{m}^{-1}$. The collapse point of DOPC appeared at a higher mean molecular area than that of DPPC (57 $\AA^{2}$ for DOPC and $37 \AA^{2}$ for DPPC), and at a lower surface pressure $\left(\pi_{\mathrm{col}}=47 \mathrm{mN} \mathrm{m}^{-1}\right.$ for DOPC and $55 \mathrm{mN} \mathrm{m}^{-1}$ for DPPC). This indicates that DOPC was more expanded and had a lower stability than DPPC (Figure S7, Supporting Information). ${ }^{36}$

The Langmuir isotherm of the $\mathrm{PDMS}_{65}-b-\mathrm{PMOXA}_{12}$ diblock copolymer had a lift-off area at $1082 \AA^{2}$, and the collapse point was reached at a surface pressure of $53 \mathrm{mN} \mathrm{m}^{-1}$, which corresponds to a mean molecular area of $60 \AA^{2} \cdot{ }^{23}$ Two plateaus resulting from polymer rearrangement during monolayer compression are present in the $\mathrm{PDMS}_{65}-b-\mathrm{PMOXA}_{12}$ isotherm (Figure 1). The first one, at a surface pressure of $12 \mathrm{mN} \mathrm{m}^{-1}$, corresponds to desorption of the hydrophobic blocks from the water surface and the formation of a monolayer. ${ }^{37}$ The second conformational rearrangement can be observed at the end of the first, long plateau at a surface pressure of $17 \mathrm{mN} \mathrm{m}^{-1}$, and represents further stretching of both hydrophobic and hydrophilic blocks and the formation of a homogeneous film. ${ }^{38}$ The rearrangements of this polymer are clearly visible in the change of the compressibility modulus values (Figure S8, Supporting Information). The maximum $C_{S}^{-1}$ value close to the collapse point $\left(44 \mathrm{mN} \mathrm{m}^{-1}\right)$ indicates that the monolayer was in the LE state. 

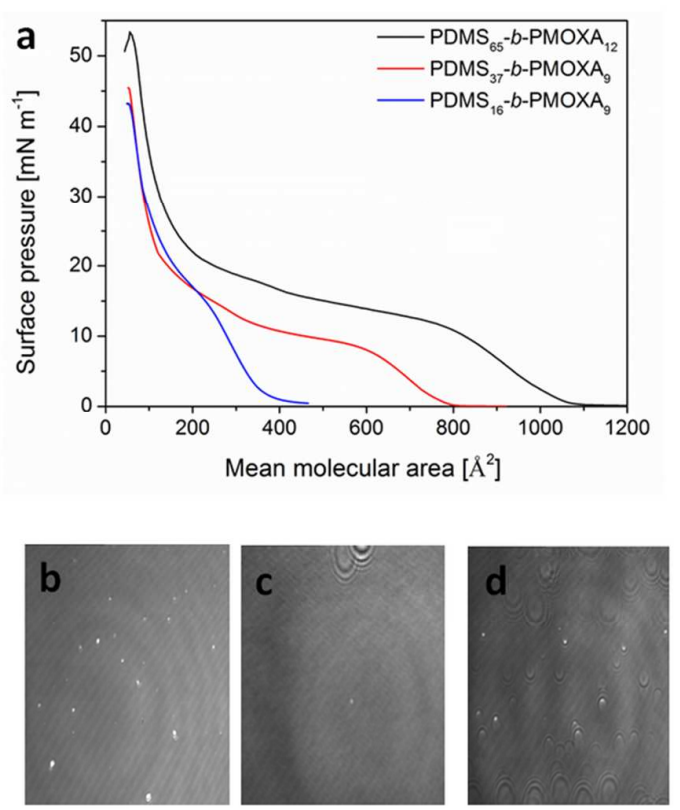

Figure 1. (a) Surface pressure-area isotherms of $\mathrm{PDMS}_{65}-b-\mathrm{PMOXA}_{12}$ (black), $\mathrm{PDMS}_{37}-b-$ $\mathrm{PMOXA}_{9}$ (red), and $\mathrm{PDMS}_{16}-b$ - $\mathrm{PMOXA}_{9}$ (blue). BAM images of (b) $\mathrm{PDMS}_{65}-b-\mathrm{PMOXA}_{12}$, (c) $\mathrm{PDMS}_{37}-b$-PMOXA 9 , and (d) $\mathrm{PDMS}_{16}-b-\mathrm{PMOXA}_{9}$ monolayers at a surface pressure of 35 $\mathrm{mN} \mathrm{m}^{-1}$.

The lift-off area decreased with decreasing number of PDMS units in the block copolymer, due to the smaller size of the copolymer, and smaller area occupied by one molecule (Figure 1, Table 1). The plateaus were shorter for $\mathrm{PDMS}_{37}-b-\mathrm{PMOXA}_{9}$ than for $\mathrm{PDMS}_{65}-b-$ PMOXA $_{12}$, whilst only one plateau was present in the isotherm of the shortest polymer $\left(\mathrm{PDMS}_{16}-b-\mathrm{PMOXA}_{9}\right)$. This result suggests that the two rearrangement states, which are pronounced in the larger polymers, overlap each other because of the limited organization possibilities. ${ }^{38}$ As expected, both shorter polymers formed monolayers at the LE state $\left(C_{S}^{-1}=\right.$ $42 \mathrm{mN} \mathrm{m}^{-1}$ for $\mathrm{PDMS}_{37}-b-\mathrm{PMOXA}_{9}$, and $36 \mathrm{mN} \mathrm{m}^{-1}$ for $\mathrm{PDMS}_{16}-b$-PMOXA, Figure $\mathrm{S} 9$, and S10 Supporting Information).

All three polymers formed homogeneous monolayers throughout the whole compression as established by BAM measurements (Figure 1, and Figure S11, Supporting Information). The 
only features that could be observed were small bright aggregates, which have been observed before also for other polymer films formed at the air-water interface, and which correspond to surface micelles formed by hydrophobic chains. ${ }^{39-41}$ The formation of these micelles is not fully understood, but the purity of the copolymer can have an influence on the size of the micelles. For example, in PDMS- $b$-PMOXA diblock copolymers some unreacted residues of PDMS can be found, which at the air-water interface will form micelles. In addition, formation the bright aggregates can be also influenced by the impurities present in the aqueous subphase.

\subsection{Surface pressure-area isotherms of mixed monolayers}

We investigated the mixing properties of all three diblock copolymers $\left(\mathrm{PDMS}_{65}-b\right.$ $\mathrm{PMOXA}_{12}, \mathrm{PDMS}_{37}-b-\mathrm{PMOXA}_{9}$, and $\left.\mathrm{PDMS}_{16}-b-\mathrm{PMOXA}_{9}\right)$ with DPPC, DOPC, DPPE, and POPE, by performing Langmuir monolayer compressions over the entire range of the molar ratios of components, i.e. polymer molar fractions $\left(x_{\text {polymer }}\right)$ of $0.25,0.50$, and 0.75 . With decreasing amount of polymer in the mixture, the mean molecular area of the monolayers decreased stepwise (Figure 2, and Figure S12 - S14, Supporting Information). The plateau span decreased, but was still visible at the lowest polymer molar fraction, suggesting separation of components in the mixtures. This is due to molecular factors, such as: i) the size difference between the polymer and lipid, and ii) different component states (LE for polymer, LC for DPPC, and S for DPPE). ${ }^{38}$ The shortest polymer, with 16 PDMS units, was most influenced by the lipids, and consequently the plateau could barely be seen in the isotherms (Figure $2 \mathrm{~b}$ ). Upon addition of lipid, the binary monolayers became more rigid, as seen by the compressibility modulus calculations (Table S1 and S2, Supporting Information). 

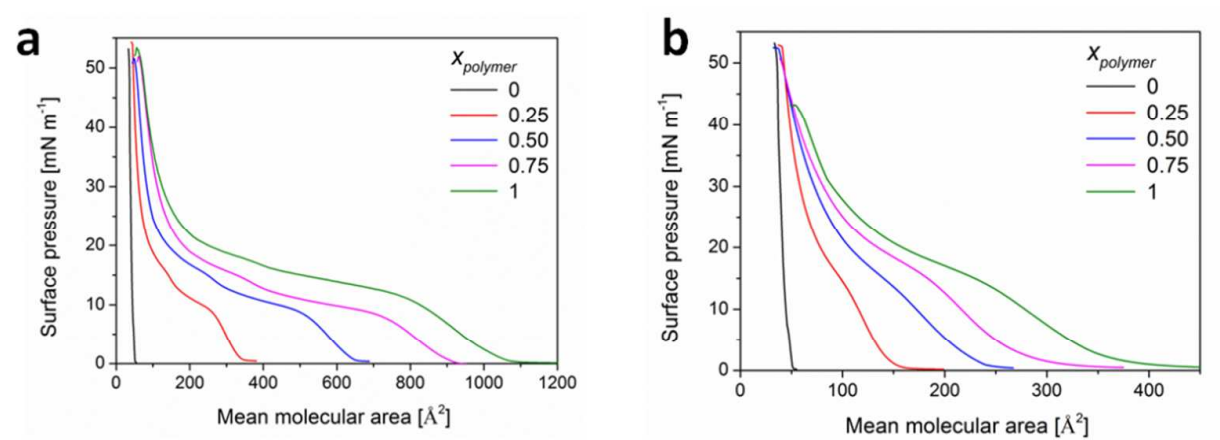

Figure 2. Representative surface pressure-area isotherms of DPPE mixed with: (a) $\mathrm{PDMS}_{65^{-}}$ $b$-PMOXA 12 and (b) PDMS $_{16}-b$-PMOXA 9 at different molar ratios.

\subsection{Phase separation for directed protein insertion}

The most important aspect in the formation of the hybrid materials is understanding their phase separation, which can be investigated by BAM. ${ }^{40}$ Phase separation occurs as a result of the different sizes and states of the components of mixtures; thus the size and amount of various domains can to a certain degree be tuned by changing the component ratios. ${ }^{40} \mathrm{We}$ were particularly interested in finding the ratios at which phase separation occurs, in order to use these systems further for controlled protein insertion.

$\mathrm{PDMS}_{65}-b-\mathrm{PMOXA}_{12}$ and $\mathrm{PDMS}_{37}-b-\mathrm{PMOXA}_{9}$ both formed domains in the presence of saturated lipids (Figure 3, and Figure S15, S16, Supporting Information), a similar behavior to that reported for mixtures of PMOXA- $b$-PDMS- $b$-PMOXA triblock copolymer and DPPC. ${ }^{40}$ It should be noted that neither BAM nor CLSM measurements provide sufficient resolution to observe phase separation at the nanoscale, thus we concentrate on investigating the mixing properties at the microscale.

At low surface pressures, we observed the formation of bright spherical domains during the compression of $\mathrm{PDMS}_{65}-b$-PMOXA 12 mixed with DPPC or DPPE $\left(x_{\text {polymer }}=0.25\right.$ and 0.5$)$ and $\mathrm{PDMS}_{65}-b-\mathrm{PMOXA}_{12}$ or $\mathrm{PDMS}_{37}-b-\mathrm{PMOXA}_{9}$ mixed with DOPC $\left(x_{\text {polymer }}=0.5\right)$, (Figure 3 a-c). We assume that these domains consist of lipids with some embedded polymer, 
since: i) the domains were bright, and thus higher than the continuous phase, ii) they appeared only at lower molar fractions of polymer, and iii) at $x_{\text {polymer }}=0.25$ the domains occupied most of the analyzed area. In order to test this assumption, polymer-lipid film labeled with a fluorescent dye (SRB) was transferred at a surface pressure of $10 \mathrm{mN} \mathrm{m}^{-1}$ and investigated by CLSM (Figure $3 \mathrm{~d}$ ). CLSM micrographs revealed a continuous phase composed of polymer (red color on the micrograph), and much darker domains that were mainly DPPC. The lipidrich domains in the CLSM micrographs are, however, not completely black, a result which indicates that labeled polymer chains were also present. ${ }^{42}$

In mixtures of the shortest polymer $\left(\mathrm{PDMS}_{16}-b-\mathrm{PMOXA}_{9}\right)$ and DPPC or DPPE, the domains appeared at higher surface pressures than with $\mathrm{PDMS}_{65}-b$-PMOXA 12 (at $14 \mathrm{mN} \mathrm{m}^{-1}$ ), and in addition were more pronounced, smaller, and with a star-like shape (Figure $3 \mathrm{f}, \mathrm{g}$ ). However they consisted of a lipid-rich phase, as established by CLSM (Figure $3 \mathrm{~h}$ ). The different shape and surface pressure (in comparison with mixtures of $\mathrm{PDMS}_{65}-b-\mathrm{PMOXA}_{12}$ and DPPC), at which the domains were formed, are due to the low thickness of $\mathrm{PDMS}_{16}-b-$ PMOXA $_{9}$, which is very close to that of DPPC $(\mathrm{d}=1.8 \mathrm{~nm}$ for polymer, and $2.1 \mathrm{~nm}$ for DPPC). Thus $\mathrm{PDMS}_{16}-b$-PMOXA, does not have a decisive influence on film formation, and the domains in this case were similar to those observed during pure DPPC compression, and correspond to the LE-LC transition of the lipid. 

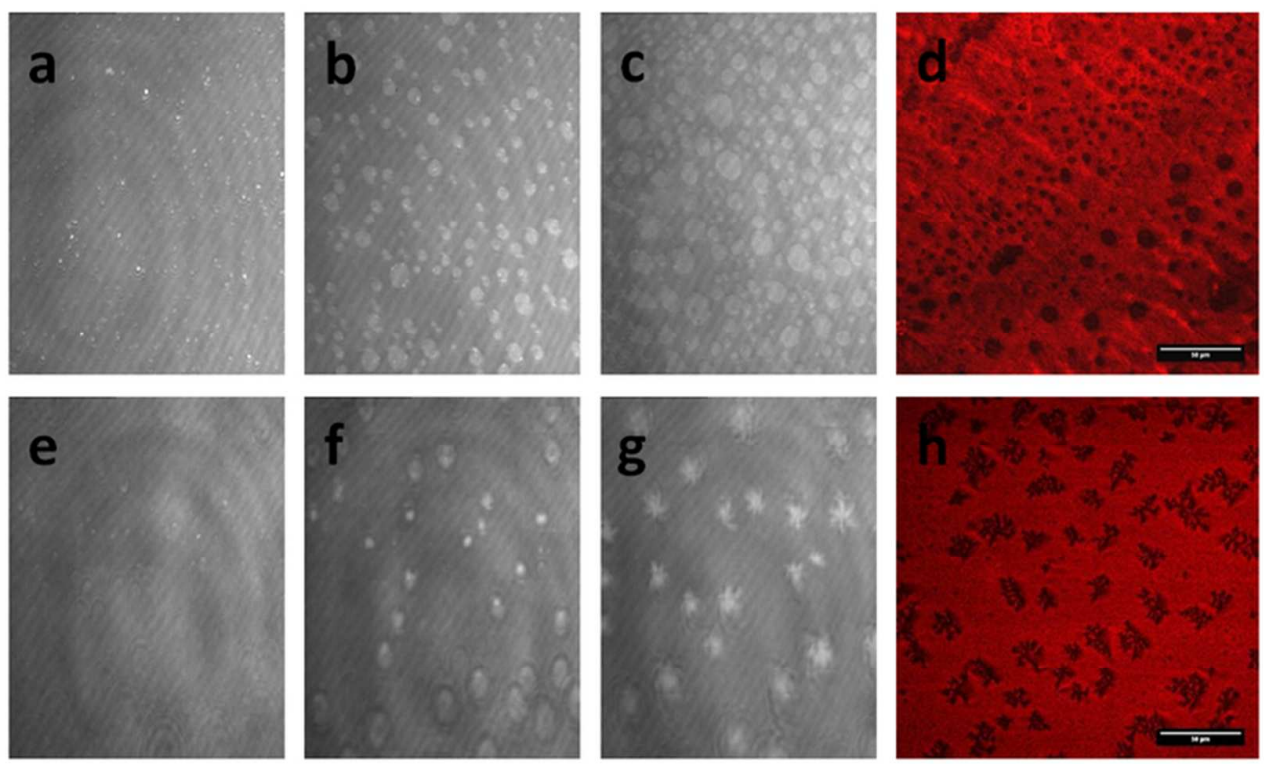

Figure 3. BAM images of monolayers from $\mathrm{PDMS}_{65}-b-\mathrm{PMOXA}_{12}-\mathrm{DPPC}$ : (a) $0.75-0.25$, (b) $0.5-0.5$, (c) $0.25-0.75\left(\right.$ at $10 \mathrm{mN} \mathrm{m}^{-1}$ ), and PDMS $16-b$-PMOXA $9-D P P C:$ (e) $0.75-0.25$, (f) $0.5-0.5,(\mathrm{~g}) 0.25-0.75\left(\right.$ at $\left.16 \mathrm{mN} \mathrm{m}^{-1}\right)$. CLSM micrographs of: (d) PDMS $65-b-\mathrm{PMOXA}_{12}-$ DPPC $\left(0.25-0.75\right.$, at $\left.10 \mathrm{mN} \mathrm{m}^{-1}\right)$, and (h) PDMS $_{16}-b$-PMOXA $9-D P P C(0.25-0.75$, at 16 $\mathrm{mN} \mathrm{m}{ }^{-1}$ ), scale bars are $50 \mu \mathrm{m}$.

These results raise the question as to why these lipid-rich domains were thicker than the continuous polymer-rich phase? The domains appeared at a surface pressure as low as $3 \mathrm{mN}$ $\mathrm{m}^{-1}$, where both components are not well organized, i.e. both DPPC and $\mathrm{PDMS}_{65}-b-$ PMOXA $_{12}$ are in a LE state. Lipid and copolymer phases separate due to size differences, and the lipid starts to expel the polymer chains from the lipid-rich phase. However, at this surface pressure, the polymer is in a so-called mushroom conformation, where both hydrophobic and hydrophilic chains are shrunken, ${ }^{38}$ and the lipid chains, which are organized vertically to the air-water interface, are thicker than the polymer chains (Figure 4). ${ }^{43,44}$ With increasing surface pressure the domains disappear as the polymer chains become stretched. 


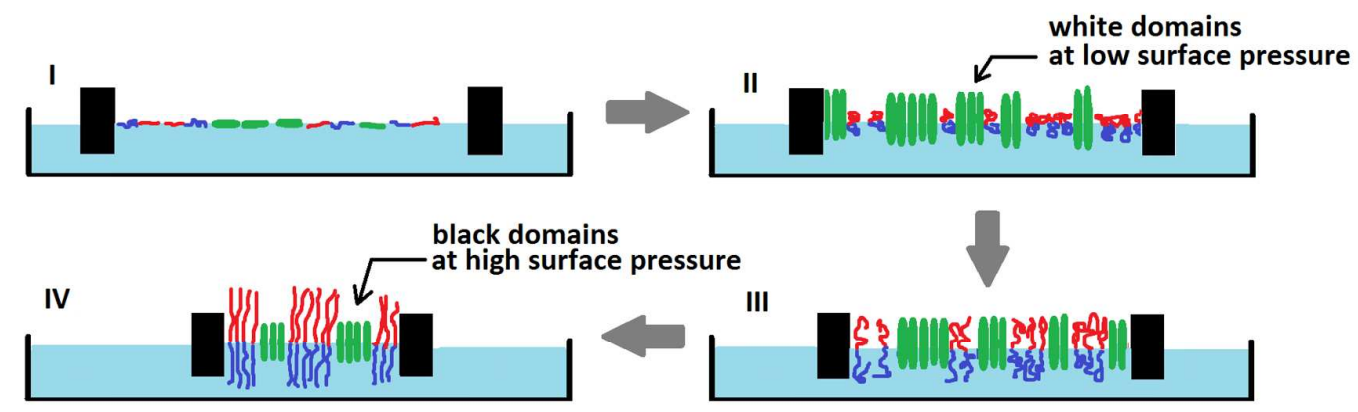

Figure 4. Scheme presenting the formation of domains in a mixed polymer-lipid monolayer, at low and high surface pressures. Molecules in green correspond to lipid and red-blue to amphiphilic block copolymer.

Upon compression of the binary monolayers at higher surface pressures, the bright domains disappeared and black domains were formed (Figure 4). These domains correspond to a lipid-rich phase, as established by CLSM measurements (Figure 5). At higher surface pressures, the monolayer is well organized, which means that the polymer chains are fully stretched and form a thicker phase than the lipids. This phenomenon was clearly observed with both $\mathrm{PDMS}_{65}-b-\mathrm{PMOXA}_{12}$ and $\mathrm{PDMS}_{37}-b-\mathrm{PMOXA}_{9}$ diblock copolymers (Figure 6). The small white aggregates observed on BAM images correspond to surface micelles formed by a hydrophobic block (PDMS) of the copolymer. ${ }^{40,41}$ 

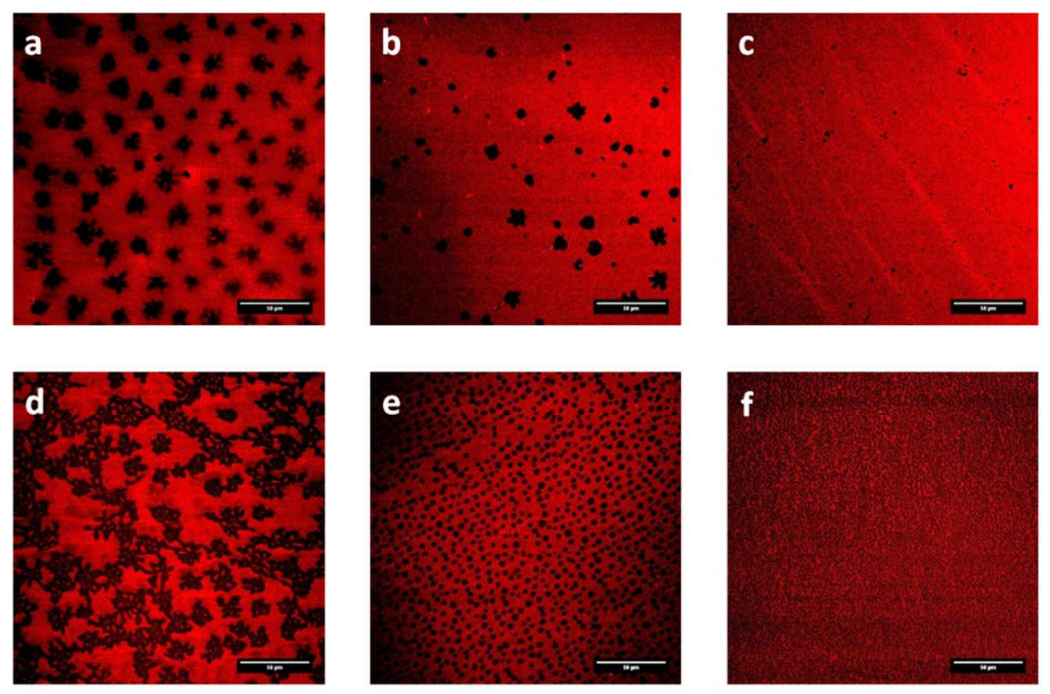

Figure 5. CLSM micrographs of: (a) $\mathrm{PDMS}_{65}-b-\mathrm{PMOXA}_{12}\left(x_{\text {polymer }}=0.25\right)-\mathrm{DPPC}$, (b) $\mathrm{PDMS}_{65}-b-\mathrm{PMOXA}_{12}\left(x_{\text {polymer }}=0.75\right)-\mathrm{DPPE},(\mathrm{c}) \mathrm{PDMS}_{65}-b-\mathrm{PMOXA}_{12}\left(x_{\text {polymer }}=0.25\right)-$ DOPC, (d) PDMS $_{37}-b-\mathrm{PMOXA}_{9} \quad\left(x_{\text {polymer }}=0.25\right)$-DPPC, $\quad$ (e) $\quad \mathrm{PDMS}_{37}-b-\mathrm{PMOXA}_{9}$ $\left(x_{\text {polymer }}=0.5\right)$-DPPE, and (f) PDMS $_{37}-b$-PMOXA $9\left(x_{\text {polymer }}=0.25\right)$-DPPE. All films were transferred at a surface pressure of $35 \mathrm{mN} \mathrm{m}^{-1}$. Scale bars are $50 \mu \mathrm{m}$.

At high surface pressures, mixtures composed of $\mathrm{PDMS}_{65}-b-\mathrm{PMOXA}_{12}$ or $\mathrm{PDMS}_{37}-b$ $\mathrm{PMOXA}_{9}$ and DPPC ( $x_{\text {polymer }}=0.25$ and 0.5$)$ formed domains with a flower-like shape. Depending on the molar ratio and the polymer used, the amount and shape of the domains varied, e.g. in mixtures of DPPC with mid-length polymer (37 PDMS units), the domains were more extended and the phase separation seemed less definitive than in $\mathrm{PDMS}_{65}-b$ PMOXA $_{12}-$ DPPC mixtures (Figure $5 \mathrm{~d}$ and 6). This behavior is due to a lower thickness of the monolayer, and thus greater interactions between lipid- and polymer-rich phases. In mixtures with DPPE, the domains were smaller and of a more regular, spherical shape. In addition, they were observed at lower lipid content $\left(x_{D P P E}=0.25\right)$ than mixtures with DPPC. The differences in size and shape of domains were the consequence of the head group of PE being smaller than that of PC and thus allowing closer packing of the molecules. ${ }^{45}$ 
Additionally, PE is it more difficult to hydrate because of the formation of intermolecular hydrogen bonds ${ }^{46}$ At the surface pressure of $35 \mathrm{mN} \mathrm{m}^{-1}$, at which domains were investigated, DPPE is in a liquid expanded state $\left(C_{S}^{-1}=173 \mathrm{mN} \mathrm{m}^{-1}\right.$, Figure S4, Supporting Information) thus it rapidly adopts spherical shape domains, to reduce the contact area with the LE polymer-rich phase.

$\mathrm{PDMS}_{16}-b$-PMOXA 9 did not form any domains at high surface pressures due to its similarity in size with the lipids, and therefore better mixing properties (Figure 6).

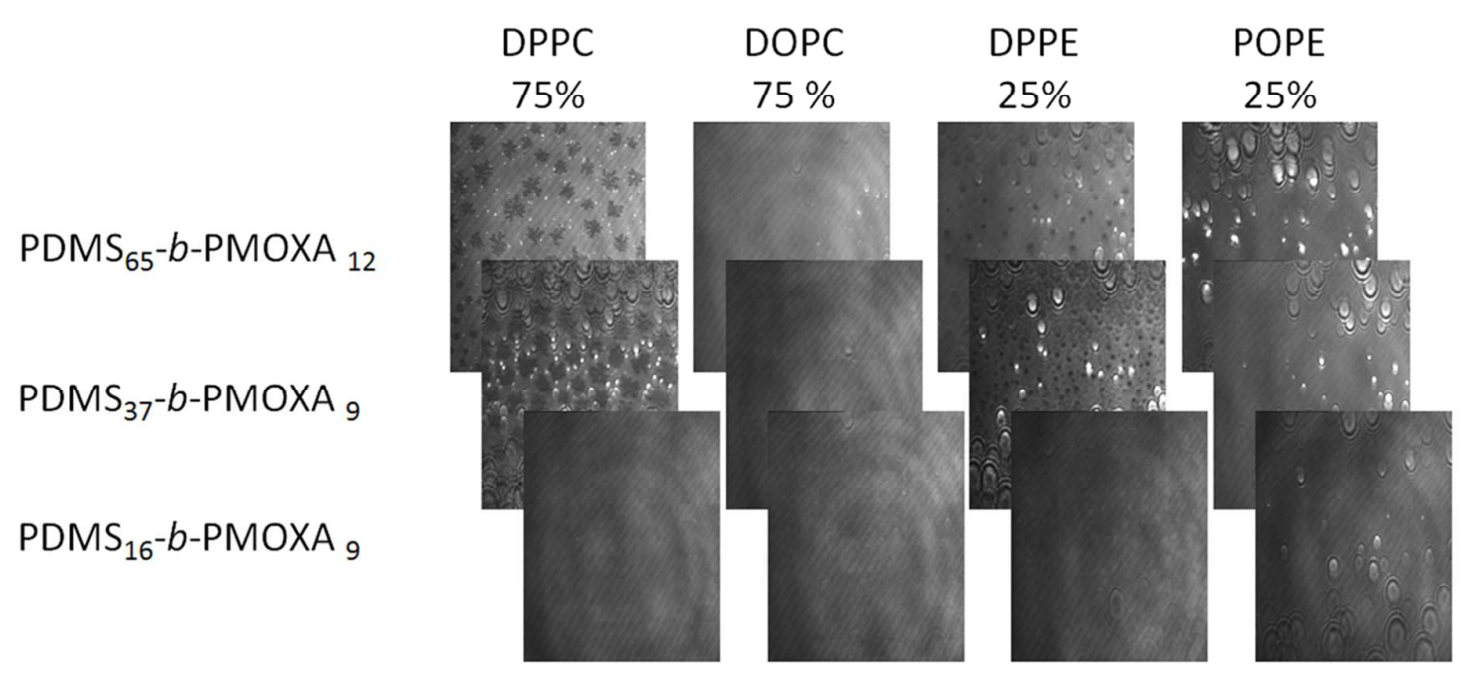

Figure 6. BAM images of PDMS- $b$-PMOXA-lipid mixtures at different molar fractions of lipids. Images were taken for a surface pressure of $35 \mathrm{mN} \mathrm{m}^{-1}$.

In the monolayer composed of $\mathrm{PDMS}_{65}-b-\mathrm{PMOXA}_{12}\left(x_{\text {polymer }}=0.25\right)$ and DOPC very small domains were observed by CLSM (Figure 5c). Otherwise, all PDMS- $b$-PMOXADOPC and PDMS- $b$-PMOXA-POPE mixtures formed uniform films for all polymers and at all molar ratios. Since all components of these mixtures are in the L or LE state, the phase separation is not as pronounced as for other mixtures with more rigid lipids, and no domains were observed at the micro-scale. ${ }^{8,46}$ 
The results obtained in this part are in good agreement with previous reports, where domain formation was observed in mixtures of polymers with DPPC, while when polymer was mixed with more liquid phospholipids, such as POPC or DOPC, homogeneous membranes were obtained. ${ }^{9,11}$ The main factors driving the phase separation in investigated mixtures were therefore: i) chemical incompatibility, ii) size mismatch, and iii) molar ratio of the mixture components.

\subsection{Protein distribution in polymer-lipid mixed films}

Prior to transferring the mixed monolayers with inserted protein, we investigated the influence of the protein on monolayer formation. The protein was injected onto the preformed mixed monolayer of $\mathrm{PDMS}_{65}-b-\mathrm{PMOXA}_{12}\left(x_{\text {polymer }}=0.25\right)$ and DPPC at a surface pressure of $20 \mathrm{mN} \mathrm{m}^{-1}$. After stabilization, the monolayer was further compressed (Figure $\mathrm{S} 3$, Supporting Information). Introduction of MloK1 into the monolayer did not change the shape of the isotherm, although the collapse point shifted to higher surface pressure (Figure 7). The collapse point of the pure mixed monolayer had a collapse point at $47 \mathrm{mN} \mathrm{m}^{-1}$, whereas the mixture with inserted protein collapsed at $52 \mathrm{mN} \mathrm{m}^{-1}$. Additionally, a change in compressibility moduli was observed, which indicates an increase in monolayer fluidity $\left(C_{s}^{-1}=69 \mathrm{mN} \mathrm{m}^{-1}\right.$ for pure monolayer and $62 \mathrm{mN} \mathrm{m}^{-1}$ for monolayer with inserted protein, Figure 7).
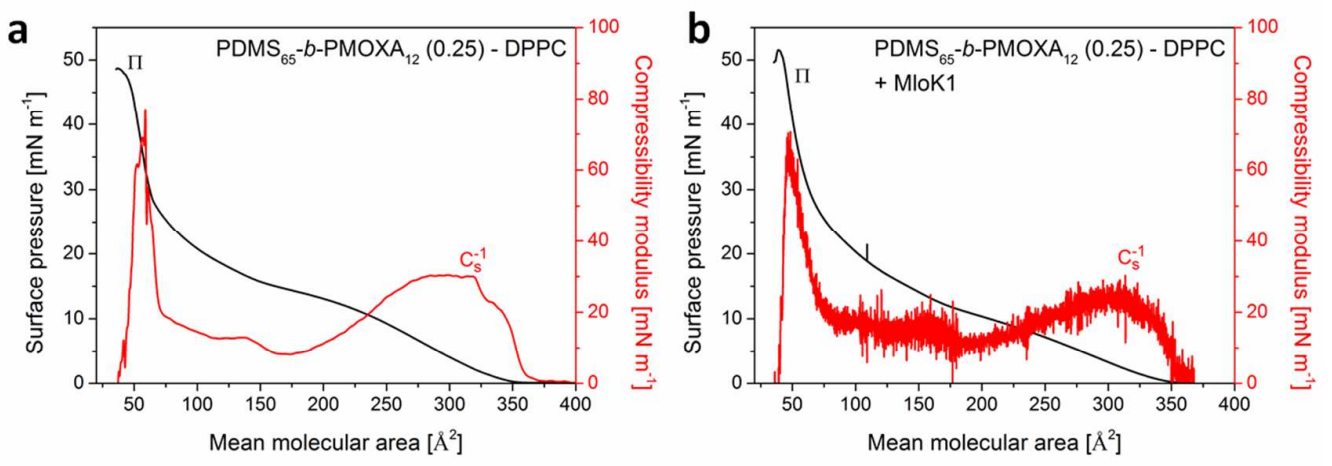
Figure 7. Surface pressure-area isotherms of $\mathrm{PDMS}_{65}-b-\mathrm{PMOXA}_{12}\left(x_{\text {polymer }}=0.25\right)$ and DPPC: (a) without and (b) with inserted protein.

An increase in the fluidity of the mixture of $\mathrm{PDMS}_{65}-b-\mathrm{PMOXA}_{12}\left(x_{\text {polymer }}=0.25\right)$ and DPPC was observed as a slight change in domain shape, as established by BAM (Figure 8). After protein insertion, the DPPC-rich domains at $35 \mathrm{mN} \mathrm{m}^{-1}$ were larger than those of the same mixture without protein. Interestingly, this expanded domain shape was similar to that in the mixture containing $30 \%$ polymer $\left(\mathrm{PDMS}_{65}-b-\mathrm{PMOXA}_{12}-\mathrm{DPPC}\right.$, no protein) at the same surface pressure. At higher polymer molar fraction, the lipid-rich domains formed at higher surface pressures, e.g. in a mixture containing $25 \%$ of polymer (no protein) the expanded domains started to form at a surface pressure of approximately $27 \mathrm{mN} \mathrm{m}^{-1}$, and were well organized as small and more spherical domains at $35 \mathrm{mN} \mathrm{m}^{-1}$ (Figure 8). For mixtures with $30 \%$ polymer, only a few small domains were observed at $27 \mathrm{mN} \mathrm{m}^{-1}$, whilst expanded domains were formed at $35 \mathrm{mN} \mathrm{m}^{-1}$, and the spherical well organized domains appeared only at a surface pressure of $40 \mathrm{mN} \mathrm{m}^{-1}$.

The change in monolayer behavior after protein insertion can be attributed to the fact that protein inserts into the polymer-rich phase, and thus increases its fraction, so that the mixture behaves as if there was $30 \%$ polymer, not $25 \%$. This hypothesis is supported by the decrease in compressibility moduli values, which was also observed for mixtures with higher polymer molar fractions. For example, the mixture with $30 \%$ of $\mathrm{PDMS}_{65}-b-\mathrm{PMOXA}_{12}$ had $C_{s}^{-1}$ close to $60 \mathrm{mN} \mathrm{m}^{-1}$. However, such pronounced changes in the domain formation process were observed only for mixtures composed of $25 \%$ PDMS- $b$-PMOXA and 75\% DPPC. In mixtures with DPPE, the domains formed were spherical and did not change their shape upon monolayer compression or protein insertion. It is due to the high stiffness of the DPPE monolayers (LC state) and formation of hydrogen bonds between the PE head-groups. In this 
case MloK1 was also inserted into the polymer-rich phase, but due to the rigid character of DPPE domains, the increased polymer fraction did not affect the shape or size of the lipid domains.
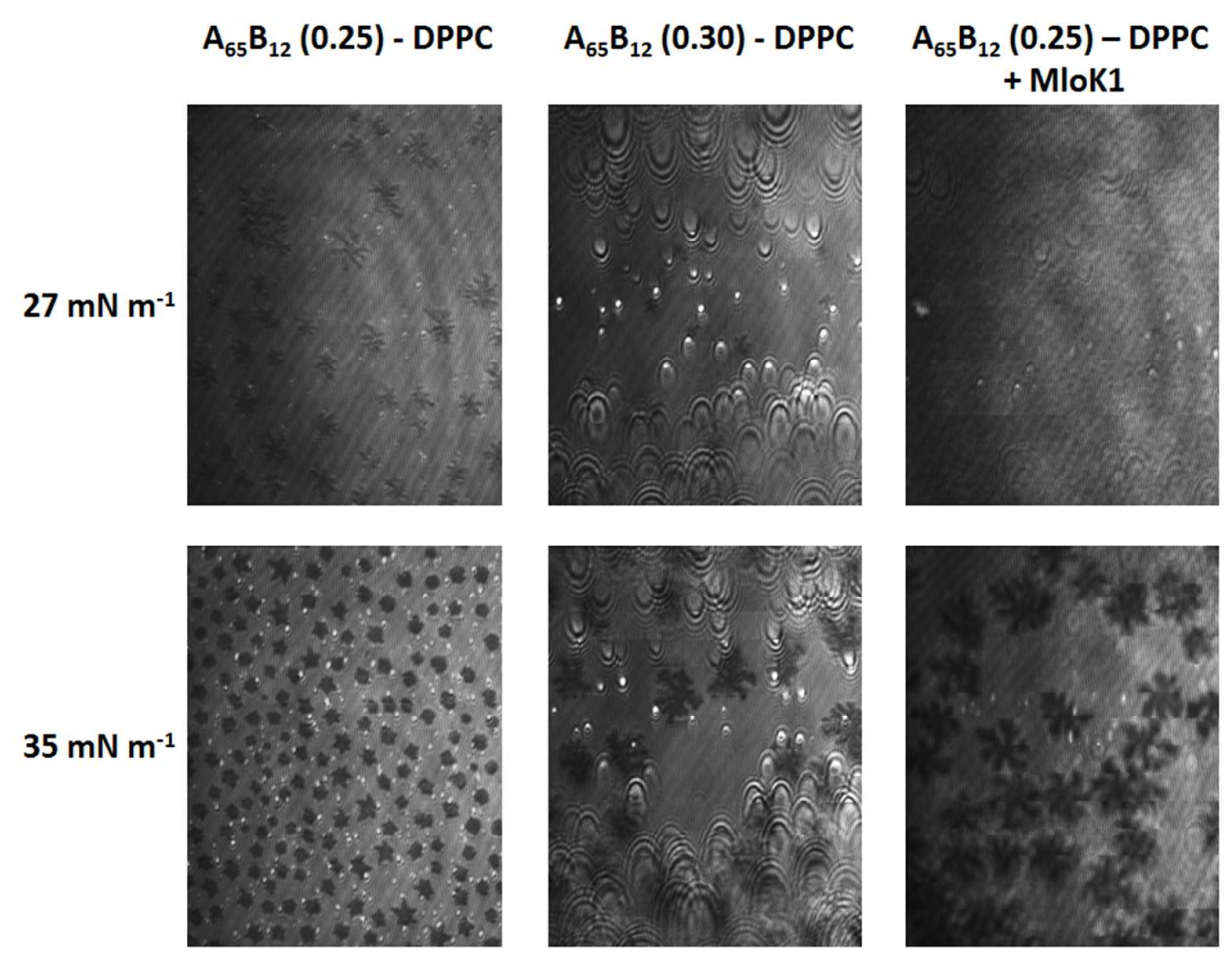

Figure 8. BAM images of $\mathrm{PDMS}_{65}-b-\mathrm{PMOXA}_{12}\left(\mathrm{~A}_{65} \mathrm{~B}_{12}\right)$ and DPPC mixtures, with and without inserted protein, at certain component ratios (given in the brackets). Images were taken at 27 and $35 \mathrm{mN} \mathrm{m}^{-1}$, and their size is $200 \times 250 \mu \mathrm{m}^{2}$.

In order to investigate the distribution of the protein, both MloK1 and the polymer were labeled with fluorescent dyes (DyLight 488 and SRB, respectively). The labeled membrane protein was inserted into mixtures containing $\mathrm{PDMS}_{65}-b-\mathrm{PMOXA}_{12}$ and $\mathrm{PDMS}_{37}-b-\mathrm{PMOXA}_{9}$ diblock copolymers, and these monolayers were then transferred to glass slides and measured by CLSM.

In mixtures containing DPPC $\left(x_{D P P C}=0.75\right.$ and 0.5$)$ and DPPE $\left(x_{D P P E}=0.25\right.$ and 0.5$)$, the protein was located entirely in the polymer-rich phase for both polymers, and the lipid- 
rich domains remained black, indicating no protein insertion (Figure $9 \mathrm{a}-\mathrm{c}, \mathrm{f}$ ). This result is in good agreement with a previous report, where $\mathrm{OmpF}$ was preferentially distributed in the polymer-rich phase of a mixture of PMOXA- $b$-PDMS- $b$ - PMOXA triblock copolymer and DPPC. ${ }^{18}$ A slight change in the DPPC-rich domains was also observed by CLSM, in good agreement with the BAM images (Figure 9 a). In the mixtures with DOPC, we observed the formation of small lipid domains, as described previously. Interestingly, here all of the protein was inserted in these spherical lipid-rich domains (Figure 9 d). A similar behavior upon insertion of the protein into a mixed film has been observed before for mixtures of lipids (POPE and POPC), where the phases also separate and form domains. Neutralizing antibodies inserted into such mixtures interacted only with the POPC-rich phase, which was the more liquid in character. ${ }^{47}$ In the uniform PDMS $_{65}-b$-PMOXA $12-$ POPE mixtures, the protein was distributed throughout the whole film (Figure 9 e).
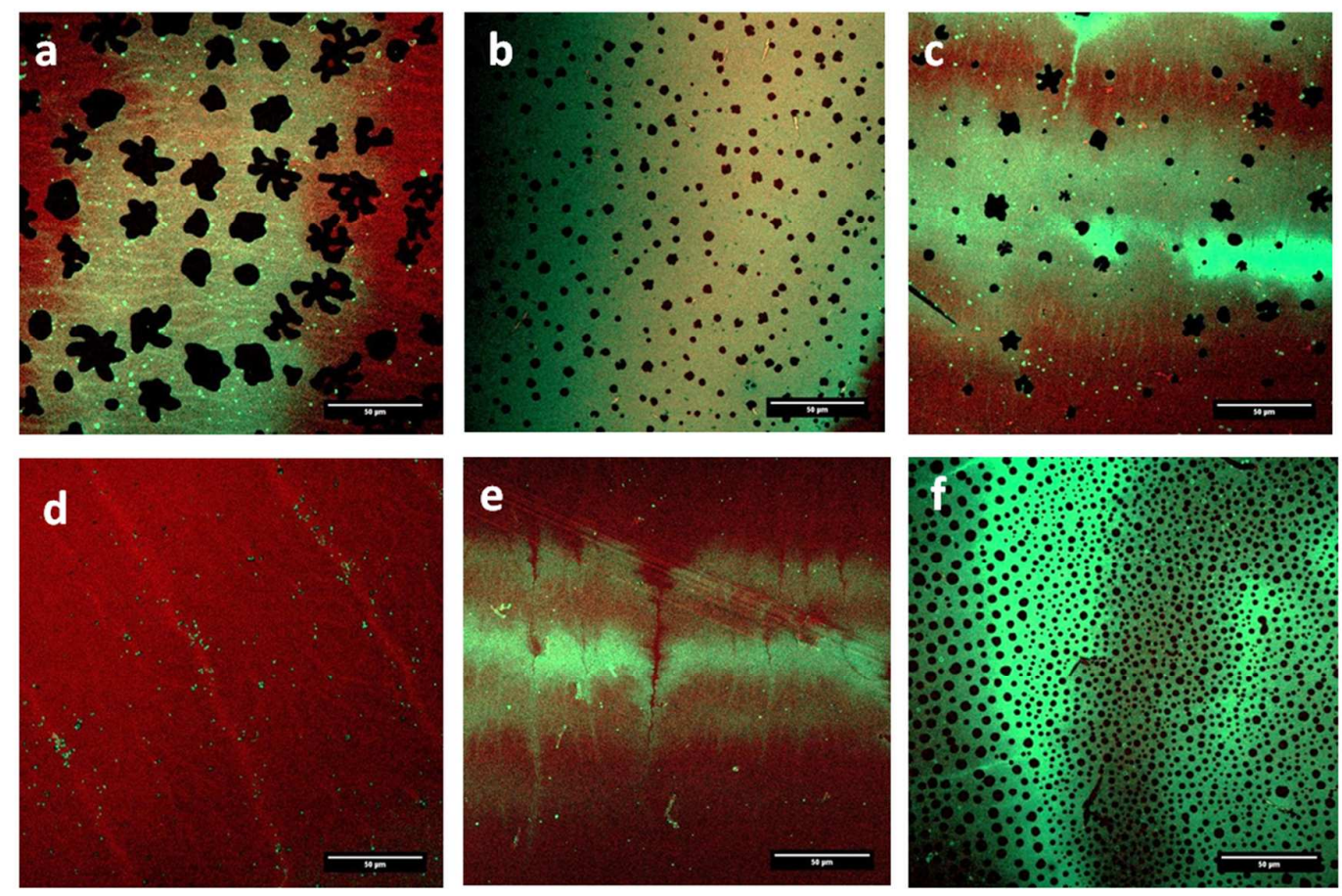

Figure 9. CLSM micrographs showing the protein distribution in films consisting of mixtures of $\mathrm{PDMS}_{65}-b-\mathrm{PMOXA}_{12}$ and: (a) DPPC $\left(x_{D P P C}=0.75\right)$, (b) DPPC $\left(x_{D P P C}=0.5\right)$, (c) DPPE $\left(x_{D P P E}=0.25\right),(\mathrm{d}) \operatorname{DOPC}\left(x_{D P P C}=0.25\right)$, and (e) POPE $\left(x_{D P P C}=0.25\right)$. (f) $\mathrm{PDMS}_{37}-b-$ 
$\mathrm{PMOXA}_{9}$ mixed with DPPE $\left(x_{D P P E}=0.5\right)$. Films were transferred at a surface pressure of 35 $\mathrm{mN} \mathrm{m}^{-1}$. Scale bars correspond to $50 \mu \mathrm{m}$.

The physical state of the components of mixtures has a crucial influence on protein distribution within the binary monolayer. DPPC and DPPE form the stiffest monolayers in the liquid condensed states. For this reason, the protein accommodates preferentially in the polymer-rich phase, which is in a liquid expanded state in mixtures containing these lipids. In this state the polymer is more flexible, has more conformational possibilities, and possesses a PDMS block of high hydrophobicity, which is able to host membrane proteins. However, if the lipid is more liquid, as for example in mixtures with DOPC, the protein inserts into the lipid-rich domains. Mixtures of $\mathrm{PDMS}_{65}-b$ - $\mathrm{PMOXA}_{12}-\mathrm{POPE}$ provide a uniform distribution of the protein in the whole monolayer, due to the similar fluidity of the mixture components.

A follow-up for this project will be further investigation of the protein behavior and functionality in such hybrid membranes. Even though it was shown that MloK1 preserves its functions after insertion into polymer membrane, ${ }^{23}$ it would be interesting to study more indepth the conformation and dynamic state of the protein incorporated in the heterogeneous membrane, for example by performing circular dichroism or electron paramagnetic resonance (EPR) studies.

\section{CONCLUSIONS}

We have developed hybrid polymer-lipid films, in which insertion of the membrane protein is triggered by a change in fluidity of the mixture. First, the properties of binary mixtures of PDMS- $b$-PMOXA diblock copolymers with selected phospholipids were investigated to establish the influence on the phase separation process of polymer size, saturation of the 1 hydrocarbon backbone chain of the lipid, and the size and character of the lipid hydrophilic head-group. Monolayer state, compressibility, and phase transitions were 
analyzed on a Langmuir trough for three diblock copolymers (having 16, 37, and 65 PDMS units) and four lipids (DPPC, DPPE, DOPC, and POPE). Changes in monolayer morphology and domain formation were monitored by Brewster angle microscopy. Mixtures, prepared with labeled polymer, were transferred by the LB technique to glass slides and investigated by confocal laser scanning microscopy. Phase separation and domain formation were most pronounced for mixtures of saturated lipids and for the larger polymers with 37 and 65 PDMS units. Due to size and state differences, these components reduced the contact area by producing lipid- and polymer-rich phases. In mixtures of the unsaturated, more liquid lipid, DOPC, the domains were so small that they were not observed by BAM. The presence of POPC induced the formation of uniform films when mixed with copolymer, and the character of the lipid head-group influenced domain formation: in mixtures with PC the domains were larger, whilst for PE, the domains were more compact and of more spherical shape.

By modulating the composition of polymer-lipid mixtures, the properties of films changed and influenced the distribution of the membrane protein. The protein was preferentially distributed in the more fluid phase, i.e. in mixtures of copolymer and saturated lipid (DPPC or DPPE) the protein inserted only into the polymer-rich phase, whereas in mixtures with unsaturated DOPC, the protein inserted into the liquid lipid-rich phase.

Finally, we have shown that it is possible to rationalize the molecular interactions between hybrid materials and membrane proteins, by regulating the distribution of the protein within hybrid films. Such ability is of high importance in development of systems with triggered behavior, for drug delivery, sensing, and the investigation of complex processes.

\section{ASSOCIATED CONTENT}

Supporting Information 


\section{AUTHOR INFORMATION}

\section{Corresponding Author}

*WM, E-mail: wolfgang.meier@unibas.ch

\section{ACKNOWLEDGMENT}

We thank the Swiss National Science Foundation, NCCR Molecular Systems Engineering, and the University of Basel for financial support. We acknowledge Prof. Dr. Henning Stahlberg (Biozentrum, University of Basel) for providing MloK1. We thank Dr. Katarzyna Kita-Tokarczyk and Fabian Itel for useful discussions and Dr. B.A. Goodman for reading the manuscript.

\section{REFERENCES}

(1) Al-Jamal, W. T.; Kostarelos, K. Liposomes: From a Clinically Established Drug Delivery System to a Nanoparticle Platform for Theranostic Nanomedicine. Acc. Chem. Res. 2011, 44, 1094-1104.

(2) Eeman, M.; Deleu, M. From Biological Membranes to Biomimetic Model Membranes. Biotechnol. Agron. Soc. 2010, 14, 719-736.

(3) Discher, D. E.; Eisenberg, A. Polymer Vesicles. Science 2002, 297, 967-973.

(4) Kita-Tokarczyk, K.; Grumelard, J.; Haefele, T.; Meier, W. Block Copolymer Vesicles-Using Concepts from Polymer Chemistry to Mimic Biomembranes. Polymer 2005, 46, 3540-3563.

(5) Robertson, J. D.; Patikarnmonthon, N.; Joseph, A. S.; Battaglia, G. Block Copolymer Micelles and Vesicles for Drug Delivery. Engineering Polymer Systems for Improved Drug Delivery 2014, 163-188. 
(6) Taubert, A.; Napoli, A.; Meier, W. Self-assembly of Reactive Amphiphilic Block Copolymers as Mimetics for Biological Membranes. Curr. Opin. Chem. Biol. 2004, 8, 598-603.

(7) Leiske, D. L.; Meckes, B.; Miller, C. E.; Wu, C.; Walker, T. W.; Lin, B. H.; Meron, M.; Ketelson, H. A.; Toney, M. F.; Fuller, G. G. Insertion Mechanism of a Poly(ethylene oxide)-poly(butylene oxide) Block Copolymer into a DPPC Monolayer. Langmuir 2011, 27, 11444-11450.

(8) Nam, J.; Beales, P. A.; Vanderlick, T. K. Giant Phospholipid/Block Copolymer Hybrid Vesicles: Mixing Behavior and Domain Formation. Langmuir 2011, 27, 1-6.

(9) Chemin, M.; Brun, P.-M.; Lecommandoux, S.; Sandre, O.; Le Meins, J.-F. Hybrid Polymer/Lipid Vesicles: Fine Control of the Lipid and Polymer Distribution in the Binary Membrane. Soft Matter 2012, 8, 2867-2874.

(10) Schulz, M.; Glatte, D.; Meister, A.; Scholtysek, P.; Kerth, A.; Blume, A.; Bacia, K.; Binder, W. H. Hybrid Lipid/Polymer Giant Unilamellar Vesicles: Effects of Incorporated Biocompatible PIB-PEO Block Copolymers on Vesicle Properties. Soft Matter 2011, 7, 8100-8110.

(11) Schulz, M.; Olubummo, A.; Bacia, K.; Binder, W. H. Lateral Surface Engineering of Hybrid Lipid-BCP Vesicles and Selective Nanoparticle Embedding. Soft Matter 2014, $10,831-839$.

(12) Schulz, M.; Werner, S.; Bacia, K.; Binder, W. H. Controlling Molecular Recognition with Lipid/Polymer Domains in Vesicle Membranes. Angew. Chem. Int. Edit. 2013, $52,1829-1833$.

(13) Le Meins, J. F.; Schatz, C.; Lecommandoux, S.; Sandre, O. Hybrid Polymer/Lipid Vesicles: State of the Art and Future Perspectives. Mater. Today 2013, 16, 397-402. 
(14) Nam, J.; Vanderlick, T. K.; Beales, P. A. Formation and Dissolution of Phospholipid Domains with Varying Textures in Hybrid Lipo-Polymersomes. Soft Matter 2012, 8, $7982-7988$.

(15) Gettel, D. L.; Sanborn, J.; Patel, M. A.; de Hoog, H. P.; Liedberg, B.; Nallani, M.; Parikh, A. N. Mixing, Diffusion, and Percolation in Binary Supported Membranes Containing Mixtures of Lipids and Amphiphilic Block Copolymers. J. Am. Chem. Soc. 2014, 136, 10186-10189.

(16) Matti, V.; Saily, J.; Ryhanen, S. J.; Holopainen, J. M.; Borocci, S.; Mancini, G.; Kinnunen, P. K. J. Characterization of Mixed Monolayers of Phosphatidylcholine and a Dicationic Gemini Surfactant SS-1 with a Langmuir Balance: Effects of DNA. Biophys. J. 2001, 81, 2135-2143.

(17) Dao, T. P. T.; Fernandes, F.; Er-Rafik, M.; Salva, R.; Schmutz, M.; Brûlet, A.; Prieto, M.; Sandre, O.; Le Meins, J. F. Phase Separation and Nanodomain Formation in Hybrid Polymer/Lipid Vesicles. ACS Macro Letters 2015, 4, 182-186.

(18) Thoma, J.; Belegrinou, S.; Rossbach, P.; Grzelakowski, M.; Kita-Tokarczyk, K.; Meier, W. Membrane Protein Distribution in Composite Polymer-Lipid Thin Films. Chem. Commun. 2012, 48, 8811-8813.

(19) Rutnakornpituk, M.; Ngamdee, P.; Phinyocheep, P. Preparation and Properties of Polydimethylsiloxane-modified Chitosan. Carbohyd. Polym. 2006, 63, 229-237.

(21) Schlaad, H.; Diehl, C.; Gress, A.; Meyer, M.; Demirel, A. L.; Nur, Y.; Bertin, A. Poly(2-oxazoline)s as Smart Bioinspired Polymers. Macromol. Rapid. Comm. 2010, $31,511-525$.

(22) Hoogenboom, R.; Schlaad, H. Bioinspired Poly(2-oxazoline)s. Polymers 2011, 3, 467488.

(23) Kowal, J.; Chami, M.; Baumgartner, P.; Arheit, M.; Chiu, P.-L.; Rangl, M.; Scheuring, S.; Schröder, G. F.; Nimigean, C. M.; Stahlberg, H. Ligand-Induced Structural 
Changes in the Cyclic Nucleotide-Modulated Potassium Channel MloK1. Nat. Comm. 2014, 5, 3106 .

(24) Kowal, J. Ł.; Kowal, J. K.; Wu, D.; Stahlberg, H.; Palivan, C. G.; Meier, W. P. Functional Surface Engineering by Nucleotide-Modulated Potassium Channel Insertion into Polymer Membranes Attached to Solid Supports. Biomaterials 2014, 35 , 7286-7294.

(25) Egli, S.; Nussbaumer, M. G.; Balasubramanian, V.; Chami, M.; Bruns, N.; Palivan, C.; Meier, W. Biocompatible Functionalization of Polymersome Surfaces: A New Approach to Surface Immobilization and Cell Targeting Using Polymersomes. J. Am. Chem. Soc. 2011, 133, 4476-4483.

(26) Wu, D.; Spulber, M.; Itel, F.; Chami, M.; Pfohl, T.; Palivan, C. G.; Meier, W. Effect of Molecular Parameters on the Architecture and Membrane Properties of 3D Assemblies of Amphiphilic Copolymers. Macromolecules 2014, 47, 5060-5069.

(27) Kazama, H.; Tezuka, Y.; Imai, K. Syntheses and Reactions of Uniform Size Poly(Dimethylsiloxane) with Various Reactive End Groups. Polym. J. 1987, 19, 10911100.

(28) Chiu, P.-L.; Pagel, M. D.; Evans, J.; Chou, H.-T.; Zeng, X.; Gipson, B.; Stahlberg, H.; Nimigean, C. M. The Structure of the Prokaryotic Cyclic Nucleotide-Modulated Potassium Channel MloK1 at 16 Å Resolution. Structure 2007, 15, 1053-1064.

(29) Harkins, W. D.; Young, T. F.; Boyd, E. The Thermodynamics of Films: Energy and Entropy of Extension and Spreading of Insoluble Monolayers. J. Chem. Phys. 1940, 8, 954-965.

(30) Virtanen, J. A.; Cheng, K. H.; Somerharju, P. Phospholipid Composition of the Mammalian Red Cell Membrane Can be Rationalized by a Superlattice Model. Proc. Natl. Acad. Sci. 1998, 95, 4964-4969. 
(31) Hauser, H.; Pascher, I.; Pearson, R. H.; Sundell, S. Preferred Conformation and Molecular Packing of Phosphatidylethanolamine and Phosphatidylcholine. Biochim. Biophys. Acta 1981, 650, 21-51.

(32) Wydro, P.; Hạc-Wydro, K. Thermodynamic Description of the Interactions between Lipids in Ternary Langmuir Monolayers: the Study of Cholesterol Distribution in Membranes. J. Phys. Chem. B 2007, 111, 2495-2502.

(33) Aroti, A.; Leontidis, E.; Maltseva, E.; Brezesinski, G. Effects of Hofmeister Anions on DPPC Langmuir Monolayers at the Air-Water Interface. J. Phys. Chem. B 2004, 108, $15238-15245$.

(34) Girard-Egrot, A. P.; Godoy, S.; Blum, L. J. Enzyme Association with Lipidic Langmuir-Blodgett Films: Interests and Applications in Nanobioscience. Adv. Colloid Interface Sci. 2005, 116, 205-225.

(35) Kanicky, J. R.; Shah, D. O. Effect of Degree, Type, and Position of Unsaturation on the $\mathrm{pK}_{\mathrm{a}}$ of Long-Chain Fatty Acids. J. Colloid Interface Sci. 2002, 256, 201-207.

(36) Domenech, O.; Ignes-Muollol, J.; Montero, M. T.; Hernandez-Borrell, J. Unveiling a Complex Phase Transition. in Monolayers of a Phospholipid from the Annular Region of Transmembrane Proteins. J. Phys. Chem. B 2007, 111, 10946-10951.

Dynarowicz-Łątka, P.; Hąc-Wydro, K. Interactions Between Phosphatidylcholines and Cholesterol in Monolayers at the Air/Water Interface. Colloids Surf. B 2004, 37, 2125.

(38) Matmour, R.; Joncheray, T. J.; Gnanou, Y.; Duran, R. S. Two-Dimensional Polymeric Nanomaterials Through Cross-Linking of Polybutadiene-b-Poly(ethylene oxide) Monolayers at the Air/Water Interface. Langmuir 2007, 23, 649-658.

(39) Haefele, T.; Kita-Tokarczyk, K.; Meier, W. Phase Behavior of Mixed Langmuir Monolayers from Amphiphilic Block Copolymers and an Antimicrobial Peptide. Langmuir 2006, 22, 1164-1172. 
(40) Joncheray, T. J.; Bernard, S. A.; Matmour, R.; Lepoittevin, B.; El-Khouri, R. J.; Taton, D.; Gnanou, Y.; Duran, R. S. Polystyrene-b-Poly(tert-butyl acrylate) and Polystyreneb-Poly(acrylic acid) Dendrimer-Like Copolymers: Two-Dimensional Self-Assembly at the Air-Water Interface. Langmuir 2007, 23, 2531-2538.

(41) Kita-Tokarczyk, K.; Itel, F.; Grzelakowski, M.; Egli, S.; Rossbach, P.; Meier, W. Monolayer Interactions between Lipids and Amphiphilic Block Copolymers. Langmuir 2009, 25, 9847-9856.

(42) Russell, T. P.: Copolymers at surfaces and interfaces. Curr. Opin. Colloid Interface Sci. 1996, 1, 107-115.

(43) Amado, E.; Kerth, A.; Blume, A.; Kressler, J. Infrared Reflection Absorption Spectroscopy Coupled with Brewster Angle Microscopy for Studying Interactions of Amphiphilic Triblock Copolymers with Phospholipid Monolayers. Langmuir 2008, 24, 10041-10053.

(44) Amado, E.; Blume, A.; Kressler, J. Novel Non-Ionic Block Copolymers Tailored for Interactions with Phospholipids. React. Funct. Polym. 2009, 69, 450-456.

(45) Ma, G.; Allen, H. C. DPPC Langmuir Monolayer at the Air-Water Interface: Probing the Tail and Head Groups by Vibrational Sum Frequency Generation Spectroscopy. Langmuir 2006, 22, 5341-5349.

(46) Korchowiec, B.; Paluch, M.; Corvis, Y.; Rogalska, E. A Langmuir film approach to elucidating interactions in lipid membranes: 1,2-dipalmitoyl-sn-glycero-3phosphoethanolamine/cholesterol/metal cation systems. Chem. Phys. Lipids 2006, 144, 127-136.

(47) Jagoda, A.; Zinn, M.; Meier, W.; Kita-Tokarczyk, K. Head Group Influence on Lipid Interactions With a Polyhydroxyalkanoate Biopolymer. Macromol. Chem. Phys. 2012, 213, 1922-1932. 
1

2

3

4

5

6

7

8

9

10

11

12

13

14

15

16

17

18

19

20

21

22

23

24

25

26

27

28

29

30

31

32

33

34

35

36

37

38

39

40

41

42

43

44

45

46

47

48

49

50

51

52

53

54

55

56

57

58

59

60
(48) Hardy, G. J.; Wong, G. C.; Nayak, R.; Anasti, K.; Hirtz, M.; Shapter, J. G.; Alam, S. M.; Zauscher, S. HIV-1 Antibodies and Vaccine Antigen Selectively Interact with Lipid Domains. Bba-Biomembranes 2014, 1838, 2662-2669. 
TOC

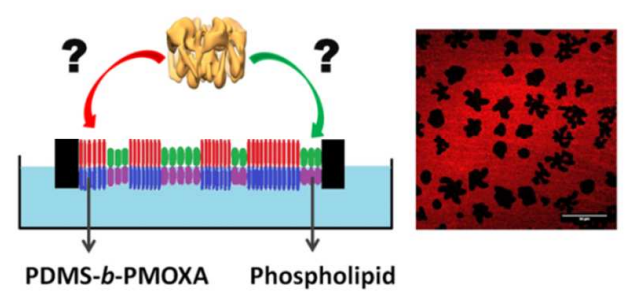

13

14

15

16

17

18

19

20

21

22

23

24

25

26

27

28

29

30

31

32

33

34

35

36

37

38

39

40

41

42

43

44

45

46

47

48

49

50

51

52

53

54

55

56

57

58

59

60 